\title{
Impact of Abdominal Aortic Calcification on Central Haemodynamics and Decline of Glomerular Filtration Rate in Patients with Chronic Kidney Disease Stages 3 and 4
}

\author{
Hanna Jansson $^{a} \quad$ Aso Saeed $^{a} \quad$ Maria K. Svensson $^{b} \quad$ Kristina Finnved $^{c}$ \\ Mikael Hellström ${ }^{c}$ Gregor Guron ${ }^{a}$ \\ a Department of Molecular and Clinical Medicine/Nephrology, Institute of Medicine, \\ Sahlgrenska Academy at the University of Gothenburg, Gothenburg, Sweden; ${ }^{b}$ Department of \\ Medical Sciences, Uppsala University, Gothenburg, Sweden; 'Department of Radiology, \\ Institute of Clinical Sciences, Sahlgrenska Academy at the University of Gothenburg, \\ Gothenburg, Sweden
}

\section{Keywords}

Ankle-brachial index $\cdot$ Pulse pressure $\cdot$ Pulse wave velocity $\cdot$ Sclerostin $\cdot$ Vascular calcification

\begin{abstract}
Background/Aim: Calcifications of large arteries are frequent in chronic kidney disease (CKD) and may contribute to the high cardiovascular risk in this population. The aim of this study was to examine whether abdominal aortic calcification volume (AACV) was a predictor of the rate of decline in glomerular filtration rate (GFR) in a cohort of patients with CKD stages 3 and 4. Methods: Eighty-four patients with CKD stages 3 and 4 were enrolled in this prospective observational study. At study entry, and annually, GFR was measured by plasma ${ }^{51} \mathrm{Cr}$-EDTA clearance. At baseline, haemodynamics was assessed and AACV was determined by computer tomography. Results: The mean follow-up time was 3.4 years and mean decline in GFR was $-2.69 \mathrm{~mL} / \mathrm{min} / 1.73 \mathrm{~m}^{2}$ per year. At baseline, abdominal aortic calcification (AAC) was detected in 66 patients (79\%). A binary logistic regression analysis revealed that age was the only statistically significant independent predictor of $A A C$. In patients with $A A C$, male gender $(B=$ $0.413, p=0.030)$, aortic diastolic blood pressure $(B=-0.025, p=0.001)$ and ankle-brachial index $(B=-1.666, p=0.002)$ were independently associated with AACV using a multiple linear regression analysis. Neither the presence nor the extent of AAC was significantly associated with the rate of change in GFR during follow-up. Conclusion: In this cohort of patients with CKD stages 3 and 4, only age was an independent predictor of the presence of AAC. AACV was not associated with the rate of decline in GFR.




\section{Kidney \\ Blood Pressure \\ Research}

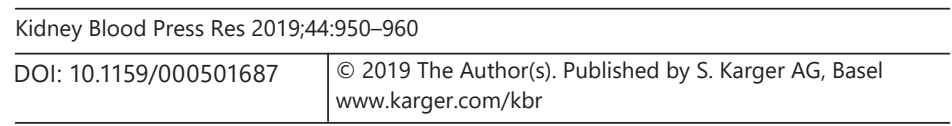

Jansson et al.: Aortic Calcification and Progression of CKD

\section{Introduction}

Chronic kidney disease (CKD) increases the risk of developing end-stage renal disease and established risk factors for disease progression are hypertension and albuminuria $[1,2]$. In addition, CKD is a strong risk factor for cardiovascular disease already when estimated glomerular filtration rate (GFR) falls below $75 \mathrm{~mL} / \mathrm{min} / 1.73 \mathrm{~m}^{2}$ [3]. Calcifications of large arteries and heart valves are prevalent in patients with CKD and might contribute to the marked increase in cardiovascular risk [4].

Previous studies have shown that the amount of abdominal aortic calcification (AAC) in non-dialysis CKD patients is an independent risk factor for cardiovascular events [5, 6]. Calcifications of large arteries may lead to alterations in central haemodynamics that have deleterious pathophysiologic effects [7]. Aortic calcification causes vascular stiffening resulting in an increase in carotid femoral pulse wave velocity (cfPWV) $[8,9]$. It has been shown that patients with CKD have a higher cfPWV compared to matched controls with normal kidney function [8], and that increased cfPWV is an independent predictor of cardiovascular mortality [10]. Although previous studies $[8,11,12]$ have shown that there is a correlation between AAC volume (AACV) and estimated GFR, the effect of AACV on kidney disease progression has not yet been determined.

The aim of the present study was to examine whether AACV could predict the rate of decline in GFR in a cohort of patients with CKD stages 3 and 4. In addition, we wanted to investigate the associations between AACV and hemodynamic variables and biomarkers sclerostin and fibroblast growth factor 23 (FGF-23). Sclerostin is a potent inhibitor of osteoblast function and decreases bone formation and mineralization [13]. Recent studies indicate that sclerostin may exert similar actions in the vascular wall, thereby inhibiting vascular calcification [14, 15]. FGF-23 is a key regulator of phosphate homeostasis and a powerful cardiovascular risk factor in CKD [16]. Still, it is unclear whether FGF-23 affects vascular calcification through direct effects on the vascular wall [17].

\section{Methods}

\section{Subjects and Protocol}

Patients were recruited from the Nephrology outpatient clinic at the Sahlgrenska University Hospital, Gothenburg, Sweden, between February 2009 and December 2011. Newly referred patients or patients with planned follow-up within 1 month were offered to participate. The Ethics Committee of the University of Gothenburg approved the study. The research was conducted in accordance with the Helsinki Declaration. All study subjects gave informed written consent to participate.

Inclusion criteria were $>18$ years of age, and an estimated GFR of $15-59 \mathrm{~mL} / \mathrm{min} / 1.73 \mathrm{~m}^{2}$ according to the MDRD formula since at least 3 months (i.e., CKD stages 3 and 4). Exclusion criteria were previous organ transplantation, ongoing immunosuppressive medication, inflammatory systemic disease, endocrine disease aside from diabetes mellitus or substituted hypothyroidism, expected survival $<12$ months, expected need of renal replacement therapy within 12 months, and pregnancy or current breast feeding. Follow-up time was up to 4 years or until start of renal replacement treatment or receiving a kidney transplant. Overall, 120 patients were recruited. Of these, 84 (70\%) agreed to do a computer tomography (CT) of the abdominal aorta to quantify AACV and these individuals were included.

At study start, a detailed medical history was gathered and the following analyses were performed: anthropometric measurements, urine and blood biochemistry, haemodynamic assessments, CT scan of the abdominal aorta, and plasma ${ }^{51} \mathrm{Cr}$-EDTA clearance to determine GFR. Plasma ${ }^{51} \mathrm{Cr}$-EDTA clearance was then measured annually.

Atherosclerotic disease was defined as a medical history of diagnosed ischaemic heart disease, cerebral infarction, transient ischemic attack or peripheral arterial disease. Diabetes mellitus was defined as a medical history of diagnosed diabetes. 


\section{Kidney Blood Pressure Research}

\begin{tabular}{l|l}
\hline Kidney Blood Press Res 2019:44:950-960 \\
\hline DOI: 10.1159/000501687 & $\begin{array}{l}\text { @ 2019 The Author(s). Published by S. Karger AG, Basel } \\
\text { www.karger.com/kbr }\end{array}$ \\
\hline
\end{tabular}

Jansson et al.: Aortic Calcification and Progression of CKD

Plasma Analyses and Measurement of GFR

At study entry, fasting blood samples were drawn and processed locally for routine analyses by standard laboratory methods at the Department of Clinical Chemistry at Sahlgrenska University Hospital (SWEDAC approved according to European norm 45001). For non-routine analyses, storage of serum was carried out at $-70^{\circ} \mathrm{C}$ until measurements were done. Sclerostin was measured by a commercially available enzymelinked immunosorbent assay kit (Biomedica, Vienna, Austria). The intra-assay coefficient of variation (CV) was $<7 \%$ and the inter-assay CV $<10 \%$. FGF-23 was measured by enzyme-linked immunosorbent assay (Kainos Laboratories Inc., Tokyo, Japan). The intra-assay CV was $<3 \%$ and the inter-assay CV $<4 \%$. Measurements were performed in duplicate for both sclerostin and FGF-23 and values were averaged. Urinary albumin creatinine ratio (UACR, $\mathrm{mg} / \mathrm{mmol}$ ) was determined in urine collected for $24 \mathrm{~h}$.

Plasma clearance of ${ }^{51} \mathrm{Cr}$-EDTA was used to measure GFR at the Department of Clinical Physiology at Sahlgrenska University Hospital according to clinical routines. The rate of change in GFR was calculated as the last obtained plasma clearance subtracted by the first ( $\Delta \mathrm{GFR}$ ) divided by the time (years) between measurements.

\section{Haemodynamic Assessments}

Ambulatory blood pressure was measured during 24 h (Spacelabs Healthcare, Model 90217). cfPWV, central aortic pressures, digital reactive hyperemia and ankle-brachial index (ABI) were measured under standardized conditions in the morning after an overnight fast by a trained research nurse with the study participant in a supine position.

By using applanation tonometry during simultaneous ECG-monitoring, the duration between the R-wave and the subsequent pressure wave was determined with SphygmoCor software (version 8, AtCor Medical, Sydney Australia). cfPWV was derived by measuring the distance between the femoral and carotid pulse, using the suprasternal notch as reference measure point, divided by the pulse transit time between the 2 locations. Central aortic blood pressures were estimated by applying a transfer function to the radial artery pressure curve (SphygmoCor, version 8, AtCor Medical, Sydney Australia) as previously described [18].

Digital reactive hyperemia was analyzed to assess endothelial function using the Endo-PAT2000 (Itamar Medical Cat. No. OM1695009) as previously described [19]. Reactive hyperemic index was calculated as the mean flow response post-occlusion using the non-occluded arm as a reference. ABI was measured using a Doppler probe and a sphygmomanometer. The mean of the indices for the posterior tibial artery and dorsalis pedis artery for each foot was calculated and the average value of the left and right foot was determined.

\section{$A A C$ Volume}

Single slice spiral CT was conducted with a GE Hi Speed CT machine (General Electric) with a tube voltage of $80 \mathrm{kV}, 250-400 \mathrm{mAs}$, tube rotation time $1.0 \mathrm{~s}$, pitch 3.0, 512 × 512 matrix and field of view (DFOV) of $48 \mathrm{~cm}$. Non-contrast enhanced CT scanning was performed with the patient in the supine position, with 3 $\mathrm{mm}$ collimation, and images were analyzed with $3 \mathrm{~mm}$ slice thickness from the Th12-L1 disc level to the top of the aortic bifurcation. AACV was measured semi-automatically on a Philips Extended Brilliance Workstation, with the HeartBeat CS application (Philips). Based on previous studies, $187 \mathrm{HU}$ was chosen as the threshold for arterial calcifications [20-22]. All tissues with a density $\geq 187 \mathrm{HU}$ were automatically colour highlighted and calcifications located within arterial vessel walls were manually selected by marking regions of interest. The area of the calcifications was automatically multiplied by the slice thickness to obtain the calcified volume. As a measure of validity of the HU threshold for calcifications using the semi-automatic calcium scoring system, all cases were subjectively scored in consensus (K.F. and M.H.) at visual assessment as having, or not having, arterial calcifications.

\section{Statistical Analyses}

Statistical analyses were performed using the SPSS Statistics Data Editor (IBM SPSS Statistics for Windows, version 22.0. Armonk, NY, USA). Reported values are means and SDs for continuous data and proportions (\%) for categorical variables. As AACV data had a highly positively skewed distribution, log transformation was performed. Approximation to a normal distribution of the log-transformed data was confirmed by examining the histogram and normal quantile-quantile plots. Data on AACV is presented as geometric means \pm SD unless stated otherwise. Statistical significance was set at the level of $p<0.05$. Correlations between continuous data were calculated using Pearson's or Spearman's test when appropriate. The Mann-Whitney U test was used for comparing differences in continuous data between groups. Differences in frequencies were analyzed using Fisher's exact test. 
Table 1. Baseline characteristcs of study population and subgroups with (AAC+) and without (AAC-) AAC

\begin{tabular}{lcccc}
\hline & $\begin{array}{l}\text { Whole cohort } \\
(n=84)\end{array}$ & $\begin{array}{l}\text { AAC }+ \\
(n=66)\end{array}$ & $\begin{array}{l}\text { AAC- } \\
(n=18)\end{array}$ & $\begin{array}{l}p \text { value } \\
\text { (AAC+ vs. AAC-) }\end{array}$ \\
\hline Age, years & $62.3 \pm 11.3$ & $66.2 \pm 8.6$ & $47.9 \pm 7.9$ & $<0.001$ \\
Men, \% & $64(76)$ & $52(79)$ & $12(67)$ & 0.351 \\
Diabetes, \% & $23(27)$ & $21(32)$ & $2(11)$ & 0.134 \\
Atherosclerotic disease, \% & $20(24)$ & $20(30)$ & 0 & 0.005 \\
Hypertension, \% & $81(96)$ & $65(98)$ & $16(89)$ & 0.115 \\
History of smoking, \% & $42(50)$ & $35(53)$ & $7(39)$ & 0.426 \\
GFR, mL/min/1.73 m ${ }^{2}$ & $37.2 \pm 15.3$ & $37.0 \pm 15.7$ & $38.2 \pm 14.2$ & 0.703 \\
BMI, kg/m ${ }^{2}$ & $27.2 \pm 4.5$ & $27.3 \pm 4.5$ & $26.7 \pm 4.2$ & 0.479 \\
Serum creatinine, $\mu$ mol/L & $176 \pm 65$ & $174 \pm 60$ & $184 \pm 82$ & 0.939 \\
U-ACR, mg/mmoL & $51 \pm 71$ & $44 \pm 58$ & $77 \pm 101$ & 0.343 \\
Serum FGF-23, pg/mL & $165 \pm 143$ & $169 \pm 151$ & $150 \pm 115$ & 0.760 \\
Serum phosphate, mmol/L & $1.08 \pm 0.21$ & $1.07 \pm 0.21$ & $1.09 \pm 0.22$ & 0.891 \\
Serum PTH, ng/L & $108 \pm 68$ & $111 \pm 70$ & $98 \pm 58$ & 0.573 \\
Serum ionized-Ca, mmol/L & $1.24 \pm 0.05$ & $1.24 \pm 0.04$ & $1.21 \pm 0.05$ & 0.010 \\
Serum sclerostin, pmol/L & $51.9 \pm 2.5$ & $55.0 \pm 2.9$ & $40.4 \pm 3.1$ & 0.010 \\
Serum C-reactive protein, mg/L & $4.9 \pm 11.7$ & $5.6 \pm 13.0$ & $2.3 \pm 3.3$ & 0.273 \\
Serum ApoB/ApoA1 & $0.78 \pm 0.32$ & $0.77 \pm 0.33$ & $0.84 \pm 0.27$ & 0.176 \\
\hline
\end{tabular}

Values are proportions (\%) or means \pm SD.

AAC, abominal aortic calcification; FGF-23, fibroblast growth factor-23; GFR, glomerular filtration rate (measured by ${ }^{51} \mathrm{Cr}$-EDTA clearance); U-ACR, urine albumin to creatinine ratio; PTH, parathyroid hormone; Apo, apolipoprotein; BMI, body mass index.

Univariate regression analyses were designed to evaluate the relationship between clinical characteristics, hemodynamic variables and the degree of AAVC or the rate of decline in GFR. A binary logistic regression was performed to predict and identify the independent risk factors for the absence or presence of AAC (ACCor ACC+).

\section{Results}

Baseline Characteristics (Table 1)

The study population consisted of 84 participants of whom 64 (76\%) were male. The primary cause of CKD was glomerulonephritis in 31\%, renovascular disease in $20 \%$, diabetic kidney disease in $17 \%$, polycystic kidney disease in $11 \%$ and other causes in $21 \%$. Twentyseven per cent of patients had a medical history of diabetes. Mean GFR at study inclusion was $37.2 \pm 15.3 \mathrm{~mL} / \mathrm{min} / 1.73 \mathrm{~m}^{2}$. In addition, $82 \%$ of patients $(n=68)$ were treated with either angiotensin-converting enzyme inhibitors or angiotensin II receptor blockers.

AAC was detected in 66 patients (AAC+), while 18 patients had no aortic calcifications (AAC-). Median AACV was 2,576 $\mathrm{mm}^{3}$ (range 0-25,025 $\mathrm{mm}^{3}$ ). Patients with AAC+ were significantly older and had increased serum levels of ionized calcium and sclerostin, compared to AAC- patients. No AAC- patient had a medical history of atherosclerotic disease compared to $20(30 \%)$ of $A A C+$ patients. The percentage of patients taking calcium containing phosphate binders and vitamin $\mathrm{D}$ analogues did not differ significantly between $\mathrm{AAC}+(36 \%)$ and AAC- $(22 \%)$ patients $(p=0.398)$.

A binary logistic regression analysis was performed to predict the presence or absence of AAC and to identify the independent risk factors for AAC. Factors that were significantly different between $\mathrm{AAC}+$ and $\mathrm{AAC}$ - patients (age, serum levels of ionized calcium and sclerostin, and a medical history of atherosclerotic disease) were included in the analysis. Age was the 
Table 2. Haemodynamic variables at study start in the whole cohort and in subgroups with (AAC+) and without (AAC-) AAC

\begin{tabular}{lcccc}
\hline & $\begin{array}{l}\text { Whole cohort } \\
(n=84)\end{array}$ & $\begin{array}{l}\text { AAC }+ \\
(n=66)\end{array}$ & $\begin{array}{l}\text { AAC- } \\
(n=18)\end{array}$ & $\begin{array}{l}p \text { value } \\
\text { (AAC+ vs. AAC- })\end{array}$ \\
\hline cfPWV, m/s & $9.9 \pm 2.7$ & $10.5 \pm 2.7$ & $7.7 \pm 1.3$ & $<0.001$ \\
Aortic SBP, mm Hg & $127 \pm 16$ & $128 \pm 15$ & $122 \pm 20$ & 0.045 \\
Aortic DBP, mm Hg & $82 \pm 11$ & $80 \pm 11$ & $87 \pm 9$ & 0.026 \\
Aortic PP, mm Hg & $45 \pm 15$ & $48 \pm 13$ & $36 \pm 16$ & $<0.001$ \\
RHI & $2.54 \pm 0.83$ & $2.57 \pm 0.90$ & $2.41 \pm 0.56$ & 0.695 \\
ABI & $1.13 \pm 0.13$ & $1.12 \pm 0.14$ & $1.17 \pm 0.08$ & 0.034 \\
ASBP, mm Hg & $125 \pm 15$ & $125 \pm 15$ & $125 \pm 15$ & 0.728 \\
ADBP, mm Hg & $74 \pm 9$ & $73 \pm 9$ & $79 \pm 9$ & 0.034 \\
\hline
\end{tabular}

Values are means $\pm \mathrm{SD}$.

Aortic blood pressures were estimated from the radial artery pressure curve recorded by applanation tonometry as described in "Methods."

AAC, abdominal aortic calcification; cfPWV, carotid-femoral pulse wave velocity; SBP, systolic blood pressure; DBP, diastolic blood pressure; PP, pulse pressure; RHI, reactive hyperemia index; ABI, ankle brachial index; ASBP, ambulatory 24-h systolic blood pressure; ADBP, ambulatory $24 \mathrm{~h}$ diastolic blood pressure.

only significant independent predictor of AAC with an $\operatorname{Exp}(\beta)$ value of 1.20 (95\% CI 1.09$1.33, p=0.0003$ ) indicating that when age is increased by 1 year, the patient is 1.2 times more likely to develop AAC.

\section{Hemodynamic Variables at Baseline (Table 2)}

In $\mathrm{AAC}+$ patients, cfPWV, aortic PP and aortic systolic blood pressure (SBP) were significantly increased versus AAC- patients, whereas aortic diastolic blood pressure (DBP), ambulatory $24 \mathrm{~h}$ DBP (ADBP) and ABI were significantly reduced. After the exclusion of aortic PP and ADBP for the reason of multicollinearity, cfPWV, aortic SBP, aortic DBP, and ABI were included in a binary logistic regression analysis. Only cfPWV showed an independent, significant, association with the presence of AAC $(\operatorname{Exp}[\beta]$ value of $1.98,95 \%$ CI $1.19-3.30, p=$ $0.009)$. However, when age was added to the regression analysis, cfPWV was no longer statistically significant and only age (Exp $[\beta] 1.21,95 \%$ CI 1.09-1.35, $p=0.001)$ had an independent and significant association with the presence of AAC.

\section{Subgroup Analyses in Patients with ACC+}

In $\mathrm{AAC}+$ patients $(n=66,79 \%)$, male gender $\left(1,475 \pm 5.5\right.$ vs. $\left.376 \pm 3.6 \mathrm{~mm}^{3}, p=0.007\right)$ and diabetes $\left(3,154 \pm 3.6\right.$ vs. $\left.676 \pm 5.4 \mathrm{~mm}^{3}, p<0.001\right)$ were associated with increased AACV. In addition, AACV was positively correlated with age $(r=0.388, p=0.001)$, serum sclerostin $(r=0.377, p=0.002)$, cfPWV $(r=0.372, p=0.003$; Fig. 1 a) and aortic $\operatorname{PP}(r=0.336, p=0.008)$. Furthermore, AACV was negatively correlated with aortic DBP $(r=-0.600, p<0.001$; Fig. 1b), $\operatorname{ADBP}(r=-0.306, p=0.014)$ and $\mathrm{ABI}(r=-0.423, p=0.001$; Fig. $1 \mathrm{c})$.

In a multiple linear regression analysis including variables age, gender, diabetes, cfPWV, aortic DBP, $\mathrm{ABI}$ and serum sclerostin, male gender $(\mathrm{B}=0.413, p=0.030)$, aortic $\mathrm{DBP}(\mathrm{B}=$ $-0.025, p=0.001)$ and $\mathrm{ABI}(\mathrm{B}=-1.666, p=0.002)$ were independently associated with AACV.

\section{Factors Associated with the Rate of Change in GFR}

The mean rate of decline in GFR was $-2.69 \mathrm{~mL} / \mathrm{min} / 1.73 \mathrm{~m}^{2}$ per year in the whole cohort. Of 84 participants, 6 died during the follow-up, 5 had a kidney transplant and 5 started renal 
Kidney

Blood Pressure

Research
Fig. 1. Correlations between logarithmic values of AACV and (a) cfPWV ( $r=0.372, p=0.003$ ); (b) aortic DBP $(r=-0.600, p<0.001)$; and (c) ABI ( $r=-0.423, p=0.001)$. Only patients with detectable AAC $+(n=66)$ were included in the analyses. For methodology and statistical analyses, see the "Methods" section. AACV, abdominal aortic calcification volume; $\mathrm{ABI}$, ankle-brachial index; cfPWV, carotid femoral pulse wave velocity; DBP, diastolic blood pressure.

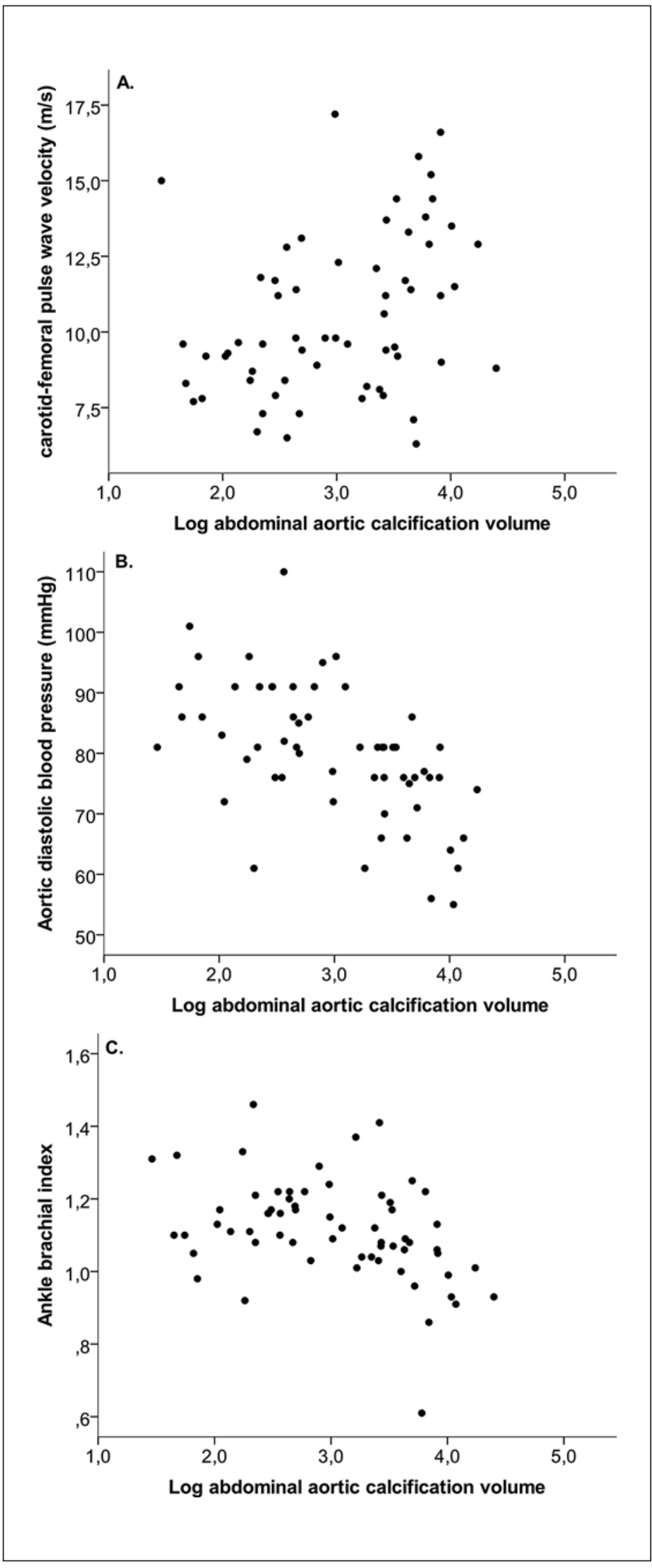




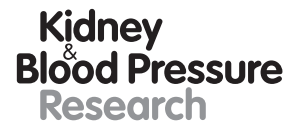

Kidney
Blood Pressure
Research

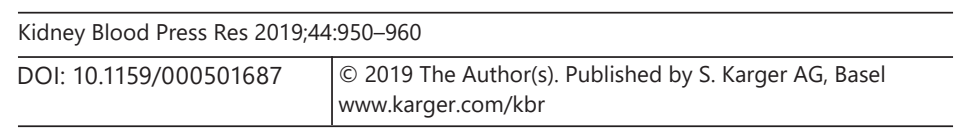

Jansson et al.: Aortic Calcification and Progression of CKD

replacement treatment. Two study participants moved to another location and 4 were lost to follow-up for unknown reasons. Mean follow-up time was $3.4 \pm 1.0$ years.

Men had a faster decline in GFR compared to women $(-3.11 \pm 3.74$ vs. $-1.36 \pm 2.25 \mathrm{~mL} /$ $\min / 1.73 \mathrm{~m}^{2}$ per year, $p=0.042$ ). There was no statistically significant difference in the rate of decline in GFR between patients with or without AAC, patients with or without diabetes or patients with or without atherosclerotic disease (data not shown).

The rate of decline in GFR was negatively correlated with baseline UACR $(r=-0.282, p=$ $0.012)$, serum FGF-23 ( $r=-0.294, p=0.007)$, serum phosphate $(r=-0.241, p=0.027)$, serum creatinine $(r=-0.343, p=0.001)$, serum parathyroid hormone $(r=-0.357, p=0.001)$, serum ApoB/ApoA1 ( $r=-0.272, p=0.013$ ), ambulatory 24-h SBP (ASBP; $r=-0.372, p=0.001$ ) and $\operatorname{ADBP}(r=-0.290, p=0.008)$. The rate of decline in GFR was positively correlated with baseline values of serum ionized calcium $(r=0.278, p=0.013)$. There were no statistically significant correlations between cfPWV $(r=0.106, p=0.35)$ or baseline GFR $(r=0.116, p=0.294)$, and the decline in GFR during follow-up.

In a univariate multiple regression analysis, including gender, UACR, serum FGF-23, serum phosphate, serum parathyroid hormone, serum creatinine, serum ionized calcium, serum ApoB/ApoA1, ASBP and ADBP, only ASBP showed an independent association with the rate of change in GFR $(\mathrm{B}=-0.098, p=0.013)$.

\section{Discussion}

In this cohort of patients with CKD stages 3 and 4, only age was an independent predictor of the presence of AAC. However, in those patients with AAC, increased AACV was independently associated with male gender and reduced aortic DBP and decreased ABI. We found no significant difference in the rate of decline in GFR between patients with, or without AAC. In addition, in patients with AAC, there was no correlation between AACV and the rate of decline in GFR during a mean follow-up of 3.4 years. Only ASBP showed an independent association with the rate of GFR decline.

Studies examining the impact of AACV on the rate of decline in GFR in patients with CKD are scarce. Calcification of the aortic arch in patients with CKD stages 3-5 has been shown to be an independent predictor of decline in GFR [23]. However, and in line with our findings, another prospective study in CKD patients with similar levels of GFR did not find a significant correlation between AACV and CKD progression [11]. The discrepant results may be partially explained by the different methods used to quantify aortic calcifications. Li et al. [23] used a semi-quantitative scoring system based on chest X-rays, whereas Hanada et al. [11] and we quantified calcifications by CT scanning, which is a more sensitive and objective method. Calcification of large arteries might have distinct effects on kidney function by causing arterial stiffening [24]. In the present study, AACV was positively correlated with cfPWV, which is a surrogate marker for aortic stiffness [25]. This relationship between aortic calcification and stiffness is consistent with previous data $[26,27]$. The elastic properties of the aorta contribute not only to provide a continuous blood flow but also to protect the sensitive organs from pulsatile pressure peaks. Because of aortic stiffening, the SBP in the aorta rises [28]. Since the renal circulation is characterized by a low resistance, a rise in SBP could be harmful to the glomeruli [24], especially if renal autoregulation is impaired [29]. In support of a pathophysiological role of aortic stiffness in kidney disease progression, Ford et al. [30] found that cfPWV was an independent predictor of GFR decline in patients with CKD stages 3 and 4. However, we found no significant correlation between cfPWV and the change in GFR during follow-up in the present study and similar results have been published by others [31, 32]. Presumably, the impact of aortic stiffness on kidney function depends on the underlying 


\section{Kidney \\ Blood Pressure \\ Research}

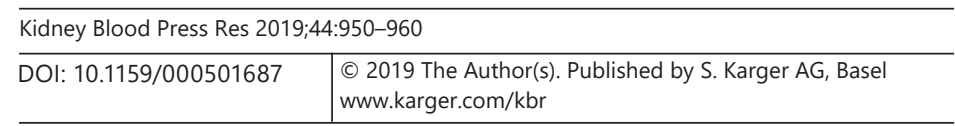

Jansson et al.: Aortic Calcification and Progression of CKD

disease. In support of this, Weir et al. [33] found a significant correlation between aortic PWV and the level of proteinuria in diabetics but not in non-diabetics. Calcification of the aorta is also likely to be associated with atherosclerosis and stenotic lesions in the renal arterial tree. Hence, in patients with severe atherosclerosis, an association between aortic calcifications and the rate of decline in GFR could be a consequence of progressive renal hypoperfusion. It is possible that these mechanisms could partially explain the results by Li et al. [23]. Compared to the present study, patients in their cohort were considerably older, had a lower GFR and diabetes was much more common.

One factor that could have influenced the results of the present study was that blood pressure was well controlled in our cohort with a mean ASBP of $125 \mathrm{~mm} \mathrm{Hg}$. In addition, 81\% of patients were treated with either angiotensin-converting enzyme inhibitor or angiotensin II receptor blockers. Moreover, the proportion of patients with glomerular diseases was low and the level of albuminuria modest (mean UACR $\approx 50 \mathrm{mg} / \mathrm{mmoL}$ ). Thus, study subjects had a relatively low risk of CKD progression, as evidenced by a mean annual decline in GFR of $-2.69 \mathrm{~mL} / \mathrm{min} / 1.73 \mathrm{~m}^{2}$, which made it difficult to detect factors that could have affected the rate of GFR decline.

The presence of AAC is a risk factor for cardiovascular mortality in dialysis patients [10, 34], which might in part be explained by aortic stiffening. Accordingly, aortic stiffness is a risk factor for cardiovascular disease in the general population [35] and has been shown to be an independent predictor of mortality in a dialysis population [36] as well as in patients with CKD stages 2-4 [37]. Increased aortic PWV leads to an early return of reflected pulse waves to the aortic root already during systole. This is likely to have deleterious effects by increasing left ventricular afterload and by compromising coronary blood perfusion during diastole. Notably, aortic DBP was significantly reduced in AAC+ versus AAC- patients in the present study and there was a significant independent association between increased AACV and reduced aortic DBP. Hence, our results support the notion that AAC might compromise coronary blood flow during diastole by reducing perfusion pressure.

In our cohort, serum sclerostin levels were significantly elevated in patients with detectable AAC and there was a positive correlation between sclerostin concentrations and AACV. However, sclerostin was not an independent predictor of AACV. A regression analysis with sclerostin as the dependent variable revealed age as an independent predictor of sclerostin (data not shown), suggesting age as a confounding factor. Previous studies have shown that serum sclerostin levels increase as GFR declines [38] and, in accordance with our data, that sclerostin concentrations correlate with the amount of cardiovascular calcifications $[14,15]$. Since sclerostin inhibits osteoblast activity [13], it has been proposed to counteract the formation of vascular calcifications. In support of this hypothesis, the local expression of sclerostin has been shown to be increased adjacent to calcified lesions in the aortic valve [14].

The main limitation of the present study was the relatively low number of included patients resulting in weak statistical power. In addition, our cohort was heterogeneous and included individuals with different kidney diseases. Also, the follow-up time was relatively short. The strength of this study was that GFR was measured annually by ${ }^{51} \mathrm{Cr}$-EDTA clearance and that patients underwent detailed hemodynamic analyses that made it possible to relate AAC to aortic function.

In conclusion, older age was the only independent predictor of the presence of AAC in our cohort of patients with CKD stages 3 and 4. Neither the presence nor the extent of AAC was significantly associated with the rate of decline in GFR during follow-up. 


\section{Acknowledgements}

The technical assistance rendered by Lotta Sundström and Inger Olander is acknowledged.

\section{Disclosure Statement}

None declared. The results presented in this paper have not been published previously in whole or in part. M.K.S. is currently employed by Amgen Sweden AB.

\section{Funding Sources}

This study was supported by grants from the Swedish Heart-Lung Foundation, Swedish Federal Government under the LUA/ALF agreement, Gothenburg Medical Society, Swedish Medical Society, Swedish Association for Kidney Patients, Swedish Society of Nephrology, Inger Bendix Foundation, Paul Frankenius Foundation, Britt Wennerström's Research Foundation, an unrestricted grant from Amgen Sweden AB, and IngaBritt and Arne Lundbergs Research Foundation. 


\begin{tabular}{l|l}
\hline \multicolumn{2}{l}{ Kidney Blood Press Res 2019;44:950-960 } \\
\hline DOI: 10.1159/000501687 & $\begin{array}{l}\text { (c) 2019 The Author(s). Published by S. Karger AG, Basel } \\
\text { www.karger.com/kbr }\end{array}$ \\
\hline
\end{tabular}

Jansson et al.: Aortic Calcification and Progression of CKD

\section{References}

1 Tangri N, Stevens LA, Griffith J, Tighiouart H, Djurdjev O, Naimark D, et al. A predictive model for progression of chronic kidney disease to kidney failure. JAMA. 2011 Apr;305(15):1553-9.

2 Hallan SI, Ritz E, Lydersen S, Romundstad S, Kvenild K, Orth SR. Combining GFR and albuminuria to classify CKD improves prediction of ESRD. J Am Soc Nephrol. 2009 May;20(5):1069-77.

3 Gansevoort RT, Correa-Rotter R, Hemmelgarn BR, Jafar TH, Heerspink HJ, Mann JF, et al. Chronic kidney disease and cardiovascular risk: epidemiology, mechanisms, and prevention. Lancet. 2013 Jul;382(9889): 339-52.

4 Oh J, Wunsch R, Turzer M, Bahner M, Raggi P, Querfeld U, et al. Advanced coronary and carotid arteriopathy in young adults with childhood-onset chronic renal failure. Circulation. 2002 Jul;106(1):100-5.

5 Peeters MJ, van den Brand JA, van Zuilen AD, Koster Y, Bots ML, Vervloet MG, et al.; MASTERPLAN Study Group. Abdominal aortic calcification in patients with CKD. J Nephrol. 2017 Feb;30(1):109-18.

6 Tatami Y, Yasuda Y, Suzuki S, Ishii H, Sawai A, Shibata Y, et al. Impact of abdominal aortic calcification on longterm cardiovascular outcomes in patients with chronic kidney disease. Atherosclerosis. 2015 Dec;243(2): 349-55.

7 Briet M, Boutouyrie P, Laurent S, London GM. Arterial stiffness and pulse pressure in CKD and ESRD. Kidney Int. 2012 Aug;82(4):388-400.

8 Temmar M, Liabeuf S, Renard C, Czernichow S, Esper NE, Shahapuni I, et al. Pulse wave velocity and vascular calcification at different stages of chronic kidney disease. J Hypertens. 2010 Jan;28(1):163-9.

9 London GM, Guérin AP, Marchais SJ, Métivier F, Pannier B, Adda H. Arterial media calcification in end-stage renal disease: impact on all-cause and cardiovascular mortality. Nephrol Dial Transplant. 2003 Sep;18(9): 1731-40.

10 Blacher J, Guerin AP, Pannier B, Marchais SJ, Safar ME, London GM. Impact of aortic stiffness on survival in end-stage renal disease. Circulation. 1999 May;99(18):2434-9.

11 Hanada S, Ando R, Naito S, Kobayashi N, Wakabayashi M, Hata T, etal. Assessment and significance of abdominal aortic calcification in chronic kidney disease. Nephrol Dial Transplant. 2010 Jun;25(6):1888-95.

12 Zhou Y, Hellberg M, Kouidi E, Deligiannis A, Höglund P, Clyne N. Relationships between abdominal aortic calcification, glomerular filtration rate, and cardiovascular risk factors in patients with non-dialysis dependent chronic kidney disease . Clin Nephrol. 2018 Dec;90(6):380-9.

13 Moester MJ, Papapoulos SE, Löwik CW, van Bezooijen RL. Sclerostin: current knowledge and future perspectives. Calcif Tissue Int. 2010 Aug;87(2):99-107.

14 Qureshi AR, Olauson H, Witasp A, Haarhaus M, Brandenburg V, Wernerson A, et al. Increased circulating sclerostin levels in end-stage renal disease predict biopsy-verified vascular medial calcification and coronary artery calcification. Kidney Int. 2015 Dec;88(6):1356-64.

15 Brandenburg VM, Kramann R, Koos R, Krüger T, Schurgers L, Mühlenbruch G, et al. Relationship between sclerostin and cardiovascular calcification in hemodialysis patients: a cross-sectional study. BMC Nephrol. 2013 Oct;14(1):219.

16 Isakova T, Ix JH, Sprague SM, Raphael KL, Fried L, Gassman JJ, et al. Rationale and approaches to phosphate and fibroblast growth factor 23 reduction in CKD. J Am Soc Nephrol. 2015 Oct;26(10):2328-39.

17 Yamada S, Giachelli CM. Vascular calcification in CKD-MBD: roles for phosphate, FGF23, and Klotho. Bone. 2017 Jul;100:87-93.

18 Chen CH, Nevo E, Fetics B, Pak PH, Yin FC, Maughan WL, et al. Estimation of central aortic pressure waveform by mathematical transformation of radial tonometry pressure. Validation of generalized transfer function. Circulation. 1997 Apr;95(7):1827-36.

19 Bonetti PO, Pumper GM, Higano ST, Holmes DR Jr, Kuvin JT, Lerman A. Noninvasive identification of patients with early coronary atherosclerosis by assessment of digital reactive hyperemia. J Am Coll Cardiol. 2004 Dec; 44(11):2137-41.

20 Thomas CK, Mühlenbruch G, Wildberger JE, Hohl C, Das M, Günther RW, et al. Coronary artery calcium scoring with multislice computed tomography: in vitro assessment of a low tube voltage protocol. Invest Radiol. 2006 Sep;41(9):668-73.

21 Nakazato R, Dey D, Gutstein A, Le Meunier L, Cheng VY, Pimentel R, et al. Coronary artery calcium scoring using a reduced tube voltage and radiation dose protocol with dual-source computed tomography. J Cardiovasc Comput Tomogr. 2009 Nov-Dec;3(6):394-400.

22 Fujioka C, Funama Y, Kiguchi M, Ishifuro M, Kihara Y, Nagata Y, et al. Coronary artery calcium scoring on different 64-detector scanners using a low-tube voltage (80 kVp). Acad Radiol. 2012 Nov;19(11):1402-7.

23 Li LC, Lee YT, Lee YW, Chou CA, Lee CT. Aortic arch calcification predicts the renal function progression in patients with stage 3 to 5 chronic kidney disease. BioMed Res Int. 2015;2015:131263.

24 O'Rourke MF, Safar ME. Relationship between aortic stiffening and microvascular disease in brain and kidney: cause and logic of therapy. Hypertension. 2005 Jul;46(1):200-4.

25 Laurent S, Cockcroft J, Van Bortel L, Boutouyrie P, Giannattasio C, Hayoz D, et al.; European Network for Noninvasive Investigation of Large Arteries. Expert consensus document on arterial stiffness: methodological issues and clinical applications. Eur Heart J. 2006 Nov;27(21):2588-605.

26 McEniery CM, McDonnell BJ, So A, Aitken S, Bolton CE, Munnery M, et al.; Anglo-Cardiff Collaboration Trial 
Investigators. Aortic calcification is associated with aortic stiffness and isolated systolic hypertension in healthy individuals. Hypertension. 2009 Mar;53(3):524-31.

27 Toussaint ND, Lau KK, Strauss BJ, Polkinghorne KR, Kerr PG. Associations between vascular calcification, arterial stiffness and bone mineral density in chronic kidney disease. Nephrol Dial Transplant. 2008 Feb; 23(2):586-93.

28 Wang MC, Tsai WC, Chen JY, Huang JJ. Stepwise increase in arterial stiffness corresponding with the stages of chronic kidney disease. Am J Kidney Dis. 2005 Mar;45(3):494-501.

29 Bidani AK, Griffin KA, Williamson G, Wang X, Loutzenhiser R. Protective importance of the myogenic response in the renal circulation. Hypertension. 2009 Aug;54(2):393-8.

30 Ford ML, Tomlinson LA, Chapman TP, Rajkumar C, Holt SG. Aortic stiffness is independently associated with rate of renal function decline in chronic kidney disease stages 3 and 4. Hypertension. 2010 May;55(5):1110-5.

31 Chue CD, Edwards NC, Davis LJ, Steeds RP, Townend JN, Ferro CJ. Serum phosphate but not pulse wave velocity predicts decline in renal function in patients with early chronic kidney disease. Nephrol Dial Transplant. 2011 Aug;26(8):2576-82.

32 Briet M, Collin C, Karras A, Laurent S, Bozec E, Jacquot C, et al.; Nephrotest Study Group. Arterial remodeling associates with CKD progression. J Am Soc Nephrol. 2011 May;22(5):967-74.

33 Weir MR, Townsend RR, Fink JC, Teal V, Anderson C, Appel L, et al. Hemodynamic correlates of proteinuria in chronic kidney disease. Clin J Am Soc Nephrol. 2011 Oct;6(10):2403-10.

34 Okuno S, Ishimura E, Kitatani K, Fujino Y, Kohno K, Maeno Y, et al. Presence of abdominal aortic calcification is significantly associated with all-cause and cardiovascular mortality in maintenance hemodialysis patients. Am J Kidney Dis. 2007 Mar;49(3):417-25.

35 Mattace-Raso FU, van der Cammen TJ, Hofman A, van Popele NM, Bos ML, Schalekamp MA, et al. Arterial stiffness and risk of coronary heart disease and stroke: the Rotterdam Study. Circulation. 2006 Feb;113(5): 657-63.

36 Blacher J, Safar ME, Guerin AP, Pannier B, Marchais SJ, London GM. Aortic pulse wave velocity index and mortality in end-stage renal disease. Kidney Int. 2003 May;63(5):1852-60.

37 Baumann M, Wassertheurer S, Suttmann Y, Burkhardt K, Heemann U. Aortic pulse wave velocity predicts mortality in chronic kidney disease stages 2-4. J Hypertens. 2014 Apr;32(4):899-903.

38 Pelletier S, Dubourg L, Carlier MC, Hadj-Aissa A, Fouque D. The relation between renal function and serum sclerostin in adult patients with CKD. Clin J Am Soc Nephrol. 2013 May;8(5):819-23. 